\title{
TREATMENT OF CHRONIC OSTEOMYELITIS OF THE LEG BY PERONEAL MYOCUTANEOUS ISLAND FLAP TRANSFER
}

\author{
MITSUO YOSHIMURA, TAKAO SHIMADA, MUNEHISA MATSUDA, \\ MASATO HOSOKAWA, SHINICHIIMURA
}

From the Fukui Medical School, Japan

\begin{abstract}
We treated 11 patients with chronic osteomyelitis of the tibia or the foot by local excision and transfer of a peroneal myocutaneous island flap. This flap, pedicled proximally or distally on the peroneal artery and veins, provides viable muscle to fill the dead space in bone and skin to close the defect. Ten patients reviewed more than three years after operation were all free of drainage with no clinical or radiographic evidence of recurrence.
\end{abstract}

Despite progress in chemotherapy and surgical treatment, chronic osteomyelitis is still a source of dissatisfaction to both the patient and the surgeon. It frequently develops after a compound fracture with extensive soft tissue injury. Management usually consists of radical excision of sequestra, sclerotic bone, scar tissue and draining sinuses, under the cover of appropriate antibiotics. Patients then may require reconstruction of the saucerised cavity and skin defect. A number of methods have been used to fill the deep cavity left after debridement. These include: bone graft (Papineau et al 1979), muscle flap (Ger and Efron 1970; Vasconez, Bostwick and McCraw 1974; Ger 1977; Briggs, Huang and Lewis 1978; Morain 1980; Salimbeni-Ughi, SantoniRugiu and de Vizia 1981; Arnold and Mixter 1983), cross-leg flap (Harrison 1968), free skin graft (Reid 1922; Knight and Wood 1945; Shannon, Woolhouse and Eisinger 1973), free flap transfer (May, Gallico and Lukash 1982), free muscle flap transfer May et al 1982, 1984), and free omental graft (Azuma et al 1976). These procedures are not always applicable or successful and in the distal leg, a common site, a local muscle flap is not always available.

We have therefore devised a new method for filling such a dead space and covering the skin defect. We use an island myocutaneous flap pedicled on the peroneal artery and vein and termed a 'peroneal myocutaneous island flap'. We report the use of this flap in 11 patients with chronic osteomyelitis involving the tibia or the foot.

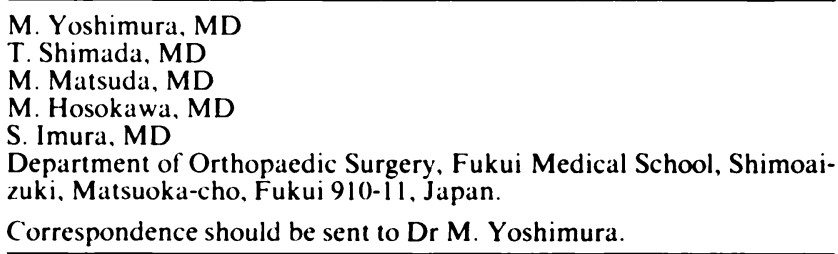

C 1989 British Editorial Society of Bone and Joint Surgery $0301-620 \mathrm{X} 894120 \$ 2.00$

J Bone Joint Surg [Br] 1989:71-B:593-6.

\section{PATIENTS AND METHODS}

A peroneal myocutaneous island flap may be indicated for treatment of chronic osteomyelitis at any site from the knee to the foot. We treated 10 patients, all with posttraumatic osteomyelitis.

At the time of treatment their ages ranged from 28 to 69 years (mean 53.2 years), and the interval since the initial injury ranged from 2 to 43 years (mean 23.7 years). All 10 patients had intermittent purulent discharge from sinus tracks. The tibia was involved in four, the calcaneus in five and metatarsals in two. Bacteriological examination was positive in all but one patient. A pre-operative angiogram was performed in all, to evaluate vascular damage or any anomalies. Follow-up after grafting ranged from three years to five years five months (mean four years, four months). The largest skin flap measured 13 by $4 \mathrm{~cm}$ and the length of the pedicle from 11 to $17.5 \mathrm{~cm}$.

Technique of operation. After radical excision of the sequestra, sclerotic bone, poor skin, and draining sinuses, the dead space was filled and the skin defect covered with a myocutaneous island flap pedicled on the peroneal artery and vein. The skin on the lateral side of the leg receives its nutrient vessels from either direct cutaneous branches or the musculocutaneous branches of the peroneal artery. The cutaneous branch runs along the posterior border of the fibula and its distribution can be easily located as 'points' with a Doppler flowmeter (Yoshimura et al 1983, 1984, 1985): Part of the soleus muscle is usually used, but the peroneal muscles or a combination of muscle tissues are sometimes employed, depending on the level of bifurcation of blood supply to the muscles.

The peroneal myocutaneous island flap may be raised either by dividing the peroneal artery and veins distally and elevating them proximally (Fig. 1) or by dividing the vessels proximally and elevating them distally (Fig. 2). The first method is used to provide cover 


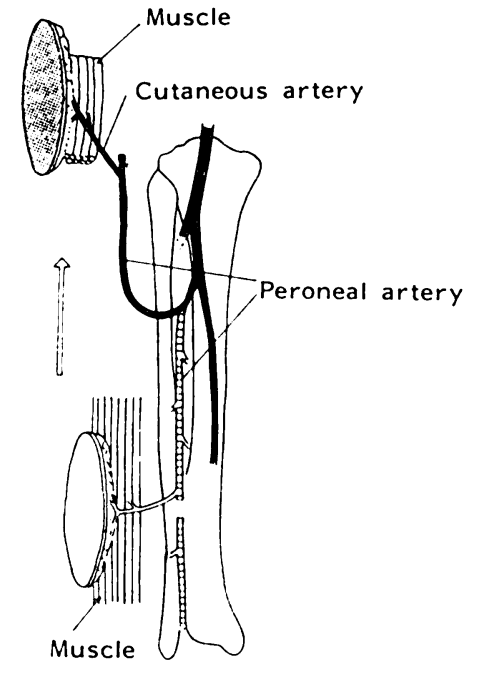

Fig. 1

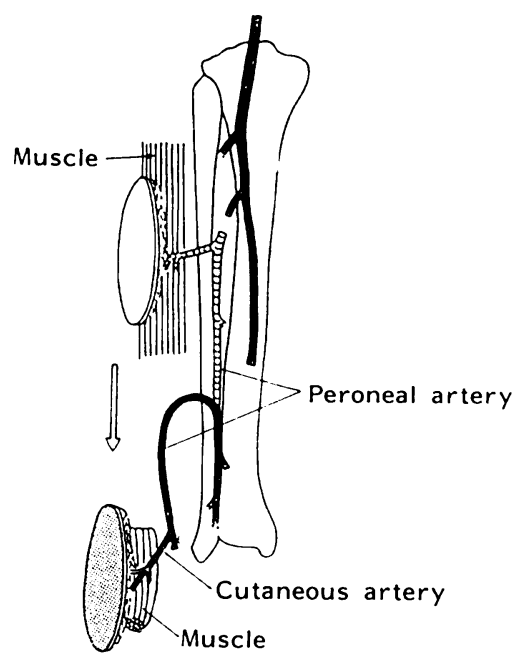

Fig. 2

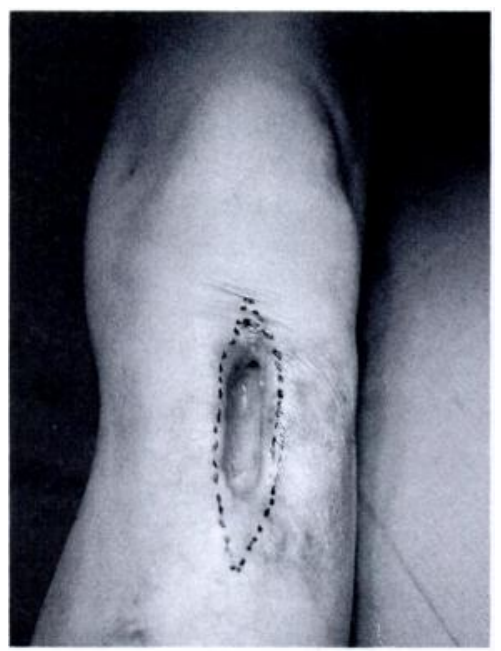

Fig. 3a

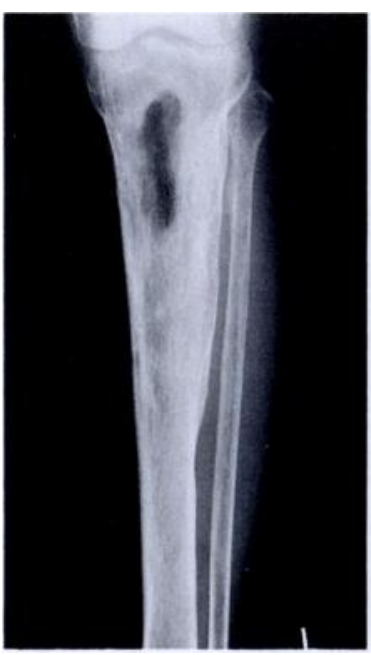

Fig. 3b
Diagrams to show the peroneal myocutaneous island flap. Figure 1 -Distal division of vessels for proximal transfer. Figure 2 - Proximal division for distal transfer.

Case 1. Chronic osteomyelitis of upper tibia, radiographs show the large cavity and cortical hypertrophy.

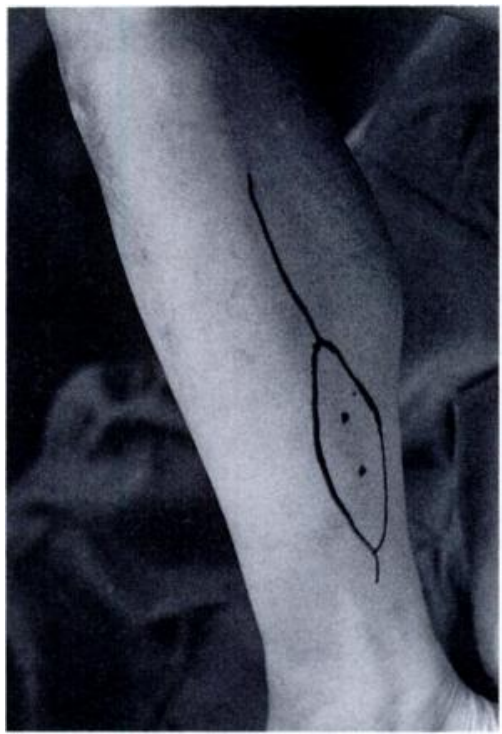

Fig. 4

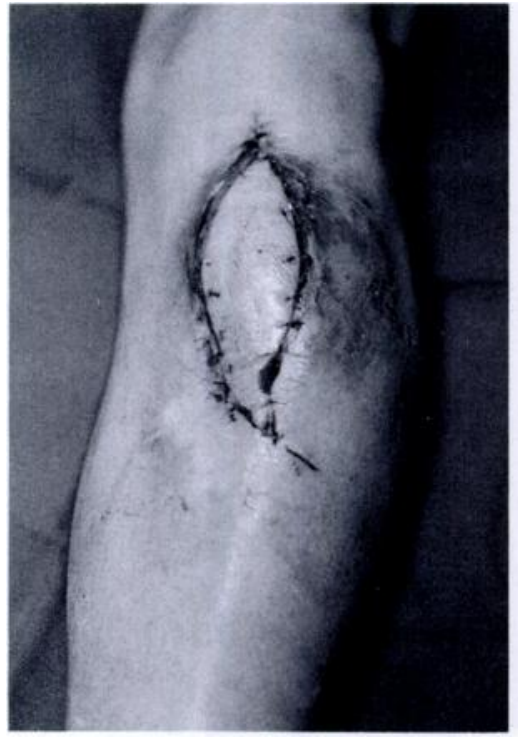

Fig. 5
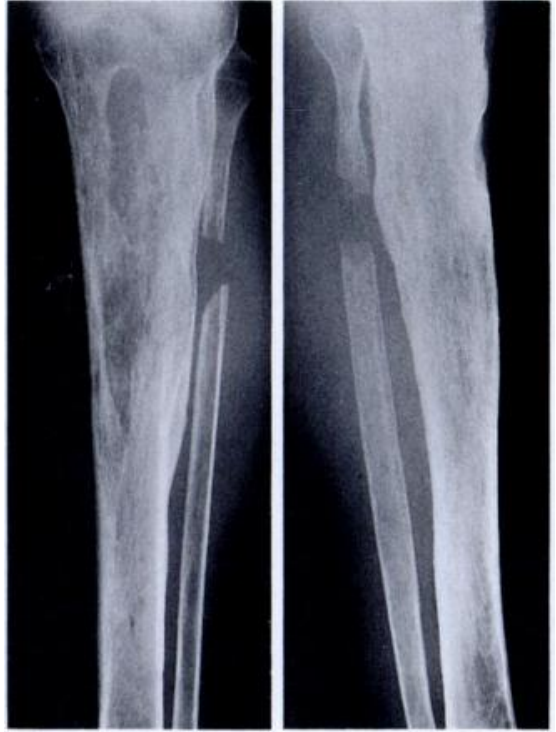

Fig. 6

Figure 4 - The $3.5 \times 12 \mathrm{~cm}$ skin flap outlined to include two determined points of entry of cutaneous arteries. Figure 5 - Myocutaneous graft inset into the defect. Figure 6 - Radiographs six weeks after operation. 
for the knee and upper leg and the second for the lower leg, ankle and foot. Venae comitantes are left intact, and the graft is completely isolated on its vascular pedicle, which is made long enough to reach the recipient site. The tourniquet is then released, demonstrating flap viability by bright red dermal bleeding from the skin margin and the ends of the muscle graft. The flap and pedicle are brought into position through a subcutaneous tunnel.

Dead space in bone is filled with the muscle graft and the skin is used to close the defect. Bipolar diathermy is used to coagulate any bleeding vessels at the edges of the flap. Direct closure of the donor site is easily achieved and suction drainage is instituted. The leg is kept in elevation for three weeks and intravenous broad-spectrum antibiotics are given for the same period; occasionally high oral dosage is continued for four to six weeks.

\section{RESULTS}

In all 10 patients the island flap survived completely with no muscle necrosis, and no complications after a minimum of three years follow-up. All patients were free of drainage and none had clinical or radiographic evidence of recurrent osteomyelitis. The period of complete bed-rest after operation ranged from 1 to 11 days (average five days) and the mean period of hospitalisation was 29 days. There were no significant deficits at donor sites and all the grafted flaps were stable and matched well.

\section{Illustrative case reports}

Case 1. A 62-year-old man had a severe compound fracture of the left leg 30 years earlier and a sinus on the anteromedial aspect of the upper shin had drained intermittently ever since (Fig. 3a). Staphylococcus epidermidis and Pseudomonas aeruginosa were cultured, and radiographs showed a cavity with some hypertrophy of the cortex (Figs $3 b$ and c).

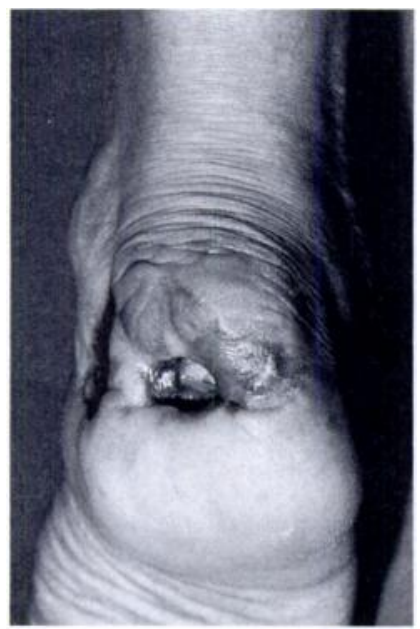

Fig. 7

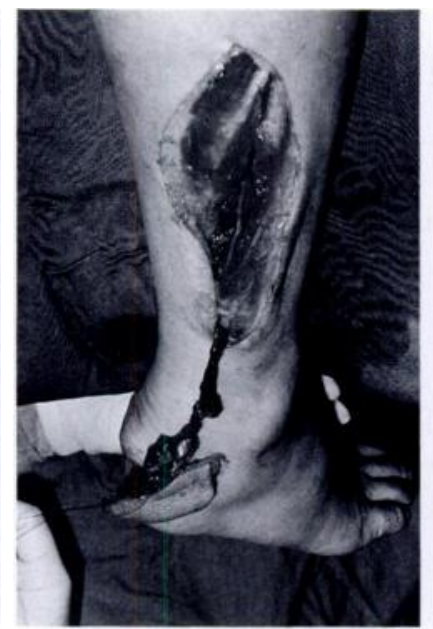

Fig. 8

After radical removal of infected and necrotic bone and soft tissue, the dead space in the tibia measured $3.5 \times 4.5 \times 10.5 \mathrm{~cm}$ and the skin defect $3.5 \times 10 \mathrm{~cm}$. A $3.5 \times 12 \mathrm{~cm}$ flap with a $2 \times 5 \times 12 \mathrm{~cm}$ block of muscle was elevated on the peroneal artery and vein (Fig. 4), and transposed $18 \mathrm{~cm}$ proximally to the recipient site. The dead space in the bone was filled with muscle and the skin defect closed (Figs 5 and 6). Antibiotics were given for two months after operation.

The wound healed in three weeks and magnetic resonance imaging at this stage showed complete filling of the dead space in the tibia. Three years after operation, the patient has no evidence of recurrent inflammation.

Case 7. A 37-year-old man developed chronic osteomyelitis after a compound fracture of the calcaneus. The site was depressed with a draining sinus on the posterior aspect of the heel (Fig. 7) and radiography showed a defect in the calcaneus. Staphylococcus epidermidis and pseudomonas were cultured.

Radical debridement was performed and a distally pedicled graft was raised (Fig. 8), giving a muscle block and a $3.5 \times 9 \mathrm{~cm}$ skin graft. This healed in 13 days (Fig. 9). The patient has had no symptoms and no recurrence of infection during the four-year follow-up (Fig. 10).

\section{DISCUSSION}

The treatment of chronic osteomyelitis requires radical excision of nonviable bone and cover for the defect if recurrence is to be prevented. Residual dead space within bone is an environment which may permit survival of bacteria and can lead to persistent or recurrent infection. Reid (1922) first suggested the use of skin grafts to cover the defect; he applied a skin graft one week or more after debridement to provide cover. Shannon et al (1973) used a partial thickness skin graft immediately after saucerisation; this took well when it was apposed to healthy soft tissue and bone.

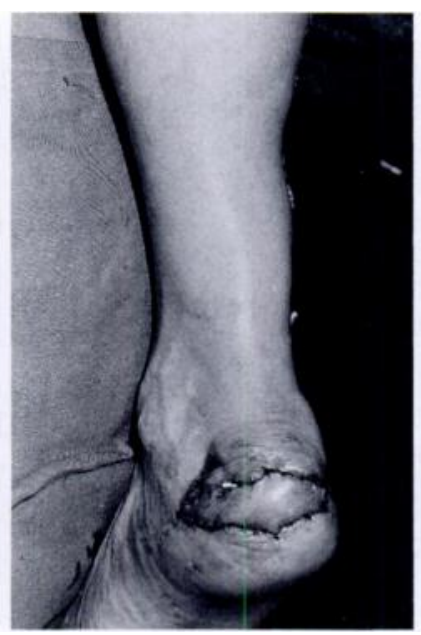

Fig. 9

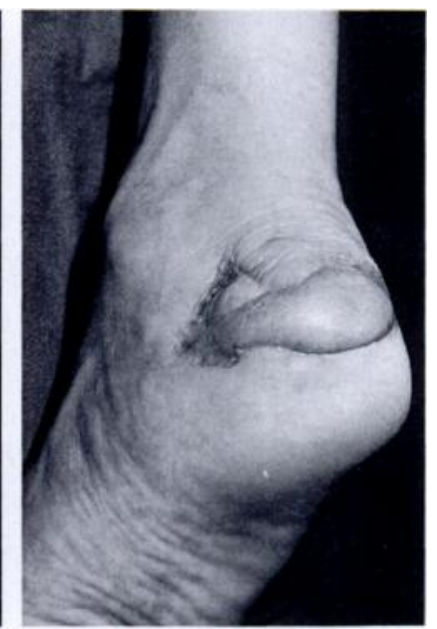

Fig. 10

Chronic infection of the calcaneus three years after compound fracture. Figure 7 - Appearance before operation. Figure 8 - Distally based flap ready for inset. Figure 9 - Graft inset into the heel. Figure 10 - Appearance three years later. 
Various techniques have been used to fill the dead space. These include: local muscle flaps (Ger and Efron 1970; Vasconez et al 1974; Ger 1977; Briggs et al 1978; Morain 1980; Salimbeni-Ughi et al 1981; Arnold and Mixter 1983), cancellous bone grafts (Papineau et al 1979), free omental graft (Azuma et al 1976), and Gentamicin-loaded polymethylmethacrylate (Vécsei and Barquet 1981). These are not always applicable or successful.

Stark (1946) recognised the effectiveness of a pedicled muscle flap. Ger and Efron (1970) and Ger (1977) reported successful treatment by debridement and cover with local muscle flaps; the use of such flaps is now accepted as a method of covering infected wounds and has been reported by a number of authors (Vasconez et al 1974; Briggs et al 1978; Morain 1980; Salimbeni-Ughi et al 1981; Arnold and Mixter 1983; Fitzgerald et al 1985). The gastrocnemius myocutaneous flap has been described by McCraw, Dibbell and Carraway (1977).

In the distal third of the tibia and the foot, the use of a pedicled muscle transplant is difficult because of the lack of available muscle (Stark 1946; Pers and Medgyesi 1973; Vasconez et al 1974; Fitzgerald et al 1985), and the merits of microvascular free tissue transfer have been pointed out (Mathes, Alpert and Chang 1982; May et al 1982, 1984; Weiland, Moore and Daniel 1984). The gracilis (Mathes et al 1982) or the latissimus dorsi (May et al 1982; 1984; Weiland et al 1984) have been used as donor muscles. Free muscle flap transfer has few limitations of recipient site, but there is a greater possibility of thrombosis.

The advantages of the peroneal myocutaneous island flap include:

1) immediate filling of dead space and cover of skin defect

2) a laterally-based pedicle, long enough to permit transfer to anywhere from the upper knee to the foot

3 ) one-stage procedure, allowing early mobilisation

4) a muscle graft which can be cut to exact size, minimising disturbance of function

5) a muscle graft with a good circulation and resistance to infection.

No benefits in any form have been received or will be received from a commercial party related directly or indirectly to the subject of this article.

\section{REFERENCES}

Arnold PG, Mixter RC. Making the most of the gastrocnemius muscles. Plast Reconstr Surg 1983:72:38-48.

Azuma H, Kondo T, Mikami M, Harii K. Treatment of chronic osteomyelitis by transplantation of autogenous omentum with microvascular anastomosis. Acta Orthop Scand 1976:47:271-5.

Briggs JG Jr, Huang TT, Lewis SR. Use of muscle flaps in treatment of osteomyelitis of the tibia. Tex Med 1978:74:82-7.

Fitzgerald RH Jr, Ruttle PE, Arnold PG, Kelly PJ, Irons GB. Local muscle flaps in the treatment of chronic osteomyelitis. J Bone Joint Surg [ Am] 1985:67-A :175-85.

Ger R, Efron G. New operative approach in the treatment of chronic osteomyelitis of the tibial diaphysis: a preliminary report. Clin Orthop 1970:70:165-9.

Ger R. Muscle transplantation for treatment and prevention of chronic post-traumatic osteomyelitis of the tibia. J Bone Joint Surg [Am] 1977:59-A :784-91.

Harrison SH. Fractures of the tibia complicated by skin loss. Br J Plast Surg 1968;21:262-76.

Knight MP, Wood GO. Surgical obliteration of bone cavities following traumatic osteomyelitis. J Bone Joint Surg 1945;27:547-56.

Mathes SJ, Alpert BS, Chang N. Use of the muscle flap in chronic osteomyelitis: experimental and clinical correlation. Plast Reconstr Surg 1982:69:815-28.

May JW Jr, Gallico GG III, Lukash FN. Microvascular transfer of free tissue for closure of bone wounds of the distal lower extremity. $N$ Engl J Med 1982:306:253-7.

May JW Jr, Gallico GG III, Jupiter J, Savage RC. Free latissimus dorsi muscle flap with skin graft for treatment of traumatic chronic bony wounds. Plast Reconstr Surg 1984;73:641-9.

McCraw JB, Dibbell DG, Carraway JH. Clinical definition of independent myocutaneous vascular territories. Plast Reconstr Surg 1977;60:341-52.

Morain WD. Soft-tissue reconstruction of below-knee defects. Am J Surg 1980:139:495-502.
Papineau LJ, Alfageme A, Dalcourt JP, Pilon L. Ostéomyélite chronique: excision et greffe de spongieux à l'air libre après mises á plat extensives. Int Orthop 1979;3:165-76.

Pers M, Medgyesi S. Pedicle muscle flaps and their applications in the surgery of repair. Br J Plast Surg 1973:26:313-21.

Reid $\mathbf{R}$. The use of large reverdin grafts in the healing of chronic osteomyelitis. Bull Johns Hopkins Univ 1922:33:386-8.

Salimbeni-Ughi G, Santoni-Rugiu P, de Vizia GP. The gastrocnemius myocutaneous flap (GMF): an alternative method to repair severe lesions of the leg. Arch Orthop Trauma Surg 1981;98: 195-200.

Shannon JG, Woolhouse FM, Eisinger PJ. The treatment of chronic osteomyelitis by saucerization and immediate skin grafting. Clin Orthop 1973:96:98-107.

Stark WJ. The use of pedicled muscle flaps in the surgical treatment of chronic osteomyelitis resulting from compound fractures. $J$ Bone Joint Surg 1946:28:343-50.

Vasconez LO, Bostwick J III, McCraw J. Coverage of exposed bone by muscle transposition and skin grafting. Plast Reconstr Surg $1974: 53: 526-30$

Vécsei V, Barquet A. Treatment of chronic osteomyelitis by necrectomy and Gentamicin-PMMA beads. Clin Orthop 1981:159:201-7.

Weiland AJ, Moore JR, Daniel RK. The efficacy of free tissue transfer in the treatment of osteomyelitis. J Bone Joint Surg [ Am] 1984;66A: $181-93$

Yoshimura M, Shimamura K, Iwai Y, Yamauchi S, Ueno T. Free vascularized fibular transplant: a new method for monitoring circulation of the grafted fibula. J Bone Joint Surg [Am] 1983;65A :1295-1301.

Yoshimura M, Imura S, Shimamura K, Yamauchi S, Nomura S. Peroneal flap for reconstruction in the extremity: preliminary report. Plast Reconstr Surg 1984;74:402-9.

Yoshimura M, Shimada T, Imura S, Shimamura K, Yamauchi S. Peroneal island flap for skin defects in the lower extremity.J Bone Joint Surg [Am] 1985:67-A :935-41. 